\title{
ANALISIS PENGETAHUAN AWAL MAHASISWA MENGENAI MASALAH INTRUSI AIR LAUT DAN ROB
}

\author{
Nur Baiti Nasution*, Sayyidatul Karimah, Hasyim As'ari \\ Program Studi Pendidikan Matematika Universitas Pekalongan \\ Korespondensi: nurbaiti.nasution@unikal.ac.id
}

\begin{abstract}
This article shows some results from the research of developing material teaching for mathematics that not only teach about mathematics but also about environmental issue, which are sea water intrusion and tidal flood. The aim of this research is to find out how far the initial knowledge of the students about sea water intrusion and tidal flood. There are five aspects about sea water intrusion and tidal flood which are discussed in this article. They are the definition, the cause, the impact, and the way to minimalize the impact. The data were collected by using questionairre and then was analyzed using descriptive method. The result shows that students know very little about sea water intrusion. They barely know the definition of it. As for the tidal flood, most of them already knew the definition, the impact, and the way to minimalize the impact. However, they know very little about the cause of tidal flood. Generally, we can conclude that their knowledge about those issues are very limited. Therefore, it is necessary to develop teaching material that not only teach about mathematics topic but also about sea water intrusion and tidal flood.
\end{abstract}

Keywords: Needs analysis, Developing material teaching, Saline intrusion and tidal flood

\begin{abstract}
ABSTRAK
Artikel ini merupakan sebagian hasil penelitian pengembangan bahan ajar matematika berbasis masalah intrusi air laut. Bahan ajar tersebut perlu dikembangkan karena masalah intrusi air laut dan rob dinilai merupakan masalah yang dekat dengan warga Pekalongan, sehingga masalah intrusi air laut dan rob dapat digunakan sebagai pengantar pada pembelajaran matematika. Akan tetapi, sebelum dilakukan pengembangan bahan ajar, terlebih dahulu perlu diketahui pengetahuan awal siswa/mahasiswa mengenai masalah intrusi air laut dan rob. Tujuan penelitian ini adalah untuk mengetahui bagaimana pengetahuan awal mahasiswa mengenai fenomena intrusi air laut dan rob. Pengetahuan awal yang dimaksud antara lain adalah pengertian intrusi air laut, pengertian rob, penyebab rob, dampak rob, dan cara menanggulangi rob. Pengumpulan data dilakukan dengan menggunakan kuesioner yang kemudian dianalisis secara deskriptif kuantitatif dan kualitatif. Dari hasil analisis diperoleh bahwa sebanyak 73\% responden belum pernah mendengar istilah intrusi air laut. Fakta lain yang diperoleh adalah bahwa sebanyak $73,38 \%$ responden familier dengan istilah rob tetapi hanya sebanyak $24 \%$ yang dapat memberikan definisi yang tepat tentang rob. Secara umum, mahasiswa responden juga belum mengetahui sepenuhnya penyebab, dampak, dan cara meminimalisir dampak rob. Dari hasil tersebut dapat disimpulkan bahwa pengetahuan mahasiswa mengenai intrusi air laut dan rob masih kurang.
\end{abstract}

Kata Kunci: pengembangan bahan ajar, intrusi air laut dan rob, matematika lingkungan.

\section{PENDAHULUAN}

Sebagai salah satu upaya untuk meningkatkan kesadaran akan masalah lingkungan hidup kepada masyarakat, Pemerintah memasukkan berbagai materi mengenai masalah lingkungan ke dalam kurikulum sekolah. Mata pelajaran yang sering digunakan sebagai pengantar mengenai masalah lingkungan adalah IPA dan Bahasa. Akan tetapi, ketika siswa mempelajari mengenai permasalahan lingkungan pada mata pelajaran IPA atau Bahasa, biasanya yang dipelajari hanya sebatas pengertian dan belum menyentuh cara penyelesaian. Padahal berlatih menyelesaikan permasalahan lingkungan secara teoritis 
dapat melatih siswa memahami masalah, membuat model matematika yang merepresentasikan masalah, menemukan strategi penyelesaian masalah, kemudian menginterpretasikan hasil penyelesaian masalah. Dengan kata lain, siswa dapat berlatih untuk memecahkan masalah.

Menurut Permendiknas No 22 Tahun 2006, salah satu tujuan pembelajaran matematika di sekolah menengah adalah untuk melatih kemampuan pemecahan masalah siswa. Dengan demikian, sangat masuk akal jika materi permasalahan lingkungan dimasukkan ke dalam materi matematika di sekolah menengah. Selain bertujuan untuk melatih kemampuan pemecahan masalah matematika siswa, hal ini juga dapat meningkatkan kesadaran siswa akan masalah lingkungan di sekitar mereka tidak hanya sebatas pada pengertiannya melainkan juga hingga langkah penyelesaiannya.

Sebagai calon guru matematika di sekolah menengah, mahasiswa Pendidikan Matematika Universitas Pekalongan perlu menguasai cara mengajarkan matematika dengan menggunakan masalah yang familiar dengan siswa. Matematika yang diajarkan dengan menggunakan masalah sehari-hari disebut matematika kontekstual atau matematika realistik. Sedangkan jika matematika diajarkan dengan masalah budaya maka disebut etnomatematika. Dalam matematika kontekstual, realistik, dan etnomatematika, guru dituntut untuk menjadi kreatif dan pandai-pandai mencari masalah yang terkait dengan kehidupan sehari-hari atau masalah budaya yang dapat digunakan untuk mengajarkan matematika. Oleh sebab itu, sejak awal ketika mahasiswa, calon guru perlu dilatih untuk menggunakan masalah sehari-hari dalam membelajarkan matematika.

Khususnya di Kota Pekalongan, permasalahan lingkungan yang sering dijumpai adalah masalah intrusi air laut dan banjir rob. Hampir sebagian besar kota Pekalongan terkena intrusi air laut dan banjir rob. Fenomena air laut menggenang pun sudah menjadi pemandangan yang biasa di sekitar kota Pekalongan. Akan tetapi, masih kurang pemanfaatan fenomena ini dalam pembelajaran matematika. Hal ini disebabkan oleh tidak ada bahan ajar matematika yang juga memuat materi mengenai intrusi air laut dan rob. Untuk itu, akan dikembangkan bahan ajar matematika yang juga mengajarkan permasalahan lingkungan yaitu intrusi air laut dan rob.

Setiap metode pengembangan bahan ajar, di antaranya metode yang dikembangkan dalam [Gall et al., 2003] dan [Thiagarajan et al., 1974], menyatakan bahwa dalam setiap tahap pengembangan bahan ajar diperlukan adanya analisis awal. Hal ini juga sesuai dengan yang disampaikan Plomp, yaitu bahwa suatu penelitian pengembangan memerlukan banyak tahapan yang mana tahapan pertama adalah preliminary research (analisis pendahuluan), yaitu analisis yang mencari tahu apa saja kebutuhan awal, pustaka yang diperlukan, dan batasan teoritis yang akan digunakan [Plomp, 2007, hal. 15]. Untuk itu, dalam upaya pengembangan bahan ajar matematika yang juga mengajarkan intrusi air laut dan banjir rob, diperlukan terlebih dahulu analisis pendahuluan.

Menurut Thiagarajan, salah satu analisis pendahuluan yang perlu dilakukan dalam pengembangan bahan ajar adalah analisis peserta didik [Thiagarajan et al., 1974, hal. 2529]. Pada tahap ini dianalisis karakter peserta didik yang menjadi sasaran pengguna produk yang dikembangkan. Karakteristik yang dimaksud meliputi pengetahuan awal, sikap dan perasaan siswa, dan preferensi siswa mengenai produk yang dikembangkan. Dalam artikel ini, variabel yang akan diteliti hanyalah pengetahuan awal saja. Karena produk yang akan dikembangkan merupakan bahan ajar matematika yang juga mengajarkan mengenai intrusi air laut dan rob, maka pengetahuan awal yang perlu dilakukan adalah pengetahuan awal 
mengenai masalah intrusi air laut dan rob. Oleh sebab itu, dilakukan penelitian yang menganalisis pengetahuan awal mahasiswa mengenai masalah intrusi air laut dan rob.

\section{METODE PENELITIAN}

Penelitian ini merupakan penelitian deskriptif yang dilaksanakan di Universitas Pekalongan dengan subyek sebanyak 37 orang mahasiswa Pendidikan Matematika Universitas Pekalongan. Pengumpulan data dilakukan dengan menggunakan kuesioner. Pertanyaan pada kuesioner meliputi 6 aspek mengenai intrusi air laut dan rob, yaitu pengertian, penyebab, dampak bagi warga, dampak bagi lingkungan hidup, cara mencegah, dan fakta-fakta terkait intrusi air laut dan rob di Kota Pekalongan.

Dugaan awal adalah bahwa istilah intrusi air tidak terlalu familiar di kalangan mahasiswa sehingga poin-poin pertanyaan pada kuesioner tidak terlalu menjurus ke intrusi air laut tetapi lebih menjurus ke rob. Dengan demikian, hanya ada satu pertanyaan yang berkaitan dengan intrusi air laut yaitu "apakah Anda mengetahui pengertian intrusi air laut?". Selain poin tersebut, pertanyaan yang diajukan lebih condong ke aspek-aspek rob. Pada bagian selanjutnya dapat dilihat bahwa hipotesis ini terbukti benar.

Setelah data terkumpul, jawaban responden untuk setiap pertanyaan diklasifikasikan secara kualitatif berdasarkan variasi jawaban yang muncul. Setelah muncul beberapa kategori, selanjutnya dihitung berapa banyak jawaban yang masuk kategori tertentu, kemudian dihitung presentasenya. Dengan menggunakan presentase ini tampak seberapa jauh pengetahuan mahasiswa mengenai intrusi air laut dan rob. Metode ini merupakan metode penelitian campuran (mixed method) [Sugiyono, 2016] .

Adapun standar yang digunakan untuk mengkategorikan hasil perhitungan adalah standar yang diadaptasi dari skala yang dibuat oleh Arikunto (Arikunto, 2010), yaitu

Tabel 1 Standar Kategorisasi

\begin{tabular}{l|l} 
Nilai Persentase & Kategori \\
\hline $0-20$ & Sangat rendah \\
\hline $21-40$ & Rendah \\
\hline $41-60$ & Agak rendah \\
\hline $61-80$ & Tinggi \\
\hline $80-100$ & Sangat tinggi
\end{tabular}

\section{HASIL DAN PEMBAHASAN}

\subsection{Pengetahuan Mengenai Pengertian Intrusi Air Laut}

Untuk mengetahui pemahaman mahasiswa mengenai intrusi air laut, pada kuesioner diberikan pertanyaan "Apakah Anda pernah mendengar istilah intrusi air laut? Jika iya, jelaskan!" Kategori jawaban yang muncul dari responden adalah pernah mendengar, belum pernah mendengar, dan tidak mengisi jawaban. Sebaran jawaban responden dapat dilihat pada Tabel 1.

Tabel 2 Jawaban untuk Pertanyaan Pernahkah Mendengar Istilah Intrusi Air Laut

\begin{tabular}{l|c|c} 
Jawab & Banyak & Presentase (\%) \\
\hline Sudah pernah mendengar & 3 & 8,11 \\
Belum pernah mendengar & 27 & 72,97 \\
Tidak mengisi & 7 & 18,92 \\
\hline Total & 37 & 100
\end{tabular}

Dari Tabel 1 tampak bahwa hampir sebanyak 73\% responden belum pernah mendengar istilah intrusi air laut dan sebanyak $18 \%$ tidak menjawab. Terdapat 3 
orang yang menjawab pernah mendengar istilah tersebut, tetapi ketika 3 orang tersebut diminta untuk menyebutkan pengertian intrusi air laut, tidak ada yang memberikan jawaban yang tepat. Jawaban ketiga responden tersebut adalah bahwa intrusi air laut merupakan "air laut yang naik ke daratan", yang mana merupakan pengertian rob [Nugroho, 2013]. Jika dibandingkan dengan Tabel 1, maka persentase mahasiswa yang sudah pernah mendengar istilah intrusi air laut dapat dikategorikan sebagai kategori rendah. Hal ini menunjukkan bahwa mahasiswa belum familiar dengan istilah intrusi air.

\subsection{Pengetahuan Mengenai Pengertian Rob}

Untuk mengetahui pemahaman mahasiswa mengenai pengertian rob, pada kuesioner diberikan pertanyaan

"Apakah Anda pernah mendengar istilah rob? Jika iya, jelaskan!"

Untuk pertanyaan tersebut, semua mahasiswa menjawab sudah pernah mendengar istilah rob. Akan tetapi, ketika diminta untuk memberikan pengertian rob, tidak semua mahasiswa dapat menjawab dengan benar.

Dari semua jawaban yang muncul, dapat dibuat beberapa kategori, yaitu jawaban benar, benar sebagian, jawaban salah, tidak menjawab. Jawaban benar yang diharapkan adalah bahwa rob merupakan kejadian dimana air laut meluap ke daratan [Nugroho, 2013]. Beberapa kasus berikut dianggap jawaban yang benar sebagian:

1. air sungai meluap ke daratan,

2. air darat lebih sedikit dari air laut, dan

3. laut meluas ke daratan.

Sedangkan jawaban mahasiswa dianggap salah, yaitu ketika menjawab bahwa rob adalah kejadian di mana:

1. pantai terkikis oleh air laut, dan

2. air laut menguap.

Sebaran jawaban mahasiswa untuk pertanyaan tersebut dapat dilihat pada Tabel 2.

Tabel 3 Jawaban untuk Pertanyaan Apakah Pengertian Rob

\begin{tabular}{l|c|c}
\multicolumn{1}{c|}{ Jawaban } & Banyak & Presentase $(\%)$ \\
\hline Benar & 29 & 73,38 \\
Benar sebagian & 3 & 8,11 \\
Salah & 3 & 8,11 \\
Tidak menjawab & 2 & 5,40 \\
\hline Total & 37 & 100
\end{tabular}

Dari tabel di atas tampak, bahwa meski masih ada beberapa mahasiswa yang tidak bisa menyebutkan pengertian rob dengan tepat, sebagian besar mahasiswa yaitu sebanyak $73,38 \%$ sudah mengetahui pengertian rob. Jika dibandingkan dengan Tabel 1, maka persentase mahasiswa yang sudah menjawab benar dapat dikategorikan sebagai kategori tinggi. Hal ini menunjukkan bahwa mahasiswa sudah familiar dengan istilah dan pengertian rob. 


\subsection{Pengetahuan Mengenai Penyebab Rob}

Untuk mengetahui sejauh mana pemahaman mahasiswa mengenai penyebab rob, pada kuesioner diberikan pertanyaan:

"Menurut pengetahuan Anda, apakah yang menjadi penyebab rob?".

Jawaban yang diperoleh dari pertanyaan tersebut cukup bervariasi. Setelah dianalisis secara kualitatif, dapat dikatakan bahwa muncul 5 pola jawaban. Yang pertama adalah ketika mahasiswa menjawab bahwa rob disebabkan oleh daratan yang lebih rendah dari permukaan air laut karena akibat dari demografi penduduk, yaitu karena adanya amblesan di permukaan tanah atau karena meningkatnya volume air laut karena pemanasan global. Menurut [Supriyadi and Khumaedi, 2016], hal ini memang dapat dianggap sebagai salah penyebab terjadinya rob. Dengan demikian, responden yang menjawab ini dapat dianggap telah memahami penyebab rob.

Pola jawaban yang kedua adalah rob terjadi karena fenomena alam seperti hujan, pasang surut air laut, dan gelombang tinggi. Hal ini pun sebenarnya dapat menjadi penyebab banjir rob, tetapi responden yang menjawab dengan pola ini secara tidak langsung menyalahkan alam untuk masalah rob. Dengan kata lain, mahasiswa yang menjawab dengan pola ini dapat merasa bahwa rob sepenuhnya merupakan fenomena alam yang tidak dapat dihindari.

Pola jawaban yang ketiga yaitu bahwa penyebab rob adalah kurangnya penahan pada pantai seperti mangrove dan tanggul. Pola jawaban yang keempat adalah mahasiswa memberikan jawaban yang sama sekali tidak berhubungan dengan rob yaitu abrasi, sumbatan selokan, dan pendangkalan pantai. Pola jawaban ketiga dan keempat menunjukkan bahwa responden memikirkan alasan mengapa air laut yang naik ke daratan bisa membanjiri rumah atau jalanan, bukan mengapa air laut dapat naik ke daratan. Hal inilah yang membedakan dengan pola jawaban yang sebelumnya. Sebaran jawaban mahasiswa dapat dilihat pada Tabel 4.

Dari hasil analisis di atas tampak bahwa mahasiswa belum sepenuhnya memahami bahwa rob merupakan fenomena yang kompleks dan dipengaruhi oleh banyak hal. Banyak yang masih beranggapan bahwa rob hanya dipengaruhi oleh satu hal tertentu bahkan menganggapnya sebagai fenomena alam. Hal ini menunjukkan bahwa pemahaman mahasiswa mengenai penyebab rob masih kurang.

Tabel 4: Jawaban untuk Pertanyaan Apakah Penyebab Rob

\begin{tabular}{|c|c|c|}
\hline Jawaban & Banyak & Presentase (\%) \\
\hline Akibat Ulah Manusia (amblesan, global warming) & 9 & 24,32 \\
\hline Fenomena Alam (hujan, pasang surut) & 7 & 18,92 \\
\hline Kurangnya penahan (mangrove, tanggul) & 9 & 24,32 \\
\hline Tidak relevan (abrasi, pendangkalan pantai) & 4 & 10,81 \\
\hline Tidak menjawab & 8 & 21,62 \\
\hline Total & 37 & 100 \\
\hline
\end{tabular}

\subsection{Pengetahuan Mengenai Dampak Rob}

Dampak rob yang dibahas dalam butir kuesioner adalah dampak rob untuk penduduk dan dampak rob bagi lingkungan hidup. Secara sekilas, dapat dilihat pada Tabel 4, bahwa sebagian mahasiswa mengetahui dampak rob bagi 
penduduk yaitu penyakit, kurang air bersih, rumah rusak dan aktivitas terganggu. Akan tetapi, untuk dampak terhadap lingkungan hidup, Tabel 5 menunjukkan bahwa masih banyak mahasiswa yang belum mengetahuinya. Dampak yang disebutkan paling banyak adalah terhambatnya pertumbuhan tanaman dan hewan. Akan tetapi, responden tidak dapat menyebutkan tumbuhan dan hewan yang seperti apa yang terhambat dengan adanya fenomena rob. Menurut [Abd-Elhamid and Javadi, 2008], ekosistem yang akan rusak jika hidup di daerah yang terkena rob adalah ekosistem yang sangat rentan terhadap perbedaan kadar garam seperti ekosistem air tawar. Banyak responden yang belum mengetahui hal ini. Selain itu, dari Tabel 5 tampak bahwa terdapat sebanyak 13 responden yang tidak menjawab poin ini. Dengan demikian, dapat disimpulkan bahwa responden belum sepenuhnya mengetahui dampak rob bagi lingkungan hidup.

Jika dibandingkan dengan Tabel 1, persentase mahasiswa yang dianggap telah memahami dampak rob bagi warga masuk dalam kategori sangat tinggi. Sedangkan persentase mahasiswa yang dianggap telah memahami dampak rob bagi lingkungan hidup masuk dalam kategori tinggi.

Tabel 5 Jawaban untuk Dampak Rob Bagi Warga

\begin{tabular}{|c|c|c|}
\hline Jawaban & Banyak & Presentase (\%) \\
\hline $\begin{array}{l}\text { Benar (Rumah rusak, banyak penyakit, aktivitas } \\
\text { terganggu) }\end{array}$ & 34 & 91,89 \\
\hline Tidak menjawab & 3 & 8,11 \\
\hline Total & 37 & 100 \\
\hline
\end{tabular}

Tabel 6 Jawaban untuk Dampak Rob Bagi Lingkungan Hidup

\begin{tabular}{l|l|l} 
Jawaban & Banyak & Presentase (\%) \\
\hline Tanaman/ hewan mati / pertumbuhan terhambat & 15 & 40,54 \\
Lingkungan kotor, air tercemar & & \\
Tidak menjawab & 9 & 24,32 \\
& 13 & 35,14 \\
\hline Total & 37 & 100
\end{tabular}

\subsection{Pengetahuan Mengenai Usaha Meminimalisasi}

Secara umum, jawaban yang diperoleh dari pertanyaan mengenai aspek ini dapat dibagi menjadi 2 pola. Yang pertama adalah pola dimana responden berpikir bagaimana agar tidak terjadi rob lagi. Jawaban yang diberikan responden pada pola ini adalah dengan membangun tanggul dan menanam bakau sebagai penahan agar rob tidak terjadi. Responden yang menjawab dengan pola ini berpikir agar dampak rob dapat diminimalisir untuk keseluruhan area tidak hanya area rumah mereka saja.

Sedangkan pola kedua yang ditemui adalah pola dimana responden berpikir bagaimana agar rob tidak mengganggu kehidupan mereka sendiri, yaitu dengan meninggikan pondasi rumah dan mengoptimalkan selokan di sekitar rumah. Sebaran jawaban responden dapat dilihat pada Tabel 6. Secara umum, mahasiswa telah dapat memahami cara-cara yang perlu dilakukan untuk mengurangi dampak rob, karena sejauh ini, cara untuk mengurangi intensitas rob adalah dengan memberikan penahan di sekitar pantai baik itu berupa mangrove ataupun tanggul [Pilgrimm, 2015], [de Melo, 2015]. 
Tabel 7 Jawaban untuk Cara Meminimalisir Dampak Rob

\begin{tabular}{c|l|l} 
Jawaban & Banyak & Presentase (\%) \\
\hline Membangun penahan (mangrove dan tanggul) & 27 & 72,97 \\
Meninggikan rumah, memompa selokan & 4 & 10,81 \\
Tidak menjawab & 6 & 16,22 \\
\hline \multicolumn{1}{c|}{ Total } & 37 & 100
\end{tabular}

\section{SIMPULAN DAN SARAN}

\subsection{Simpulan}

1. Hasil analisis menunjukkan bahwa persentase banyaknya mahasiswa yang pernah mendengar istilah intrusi air laut masuk dalam kategori sangat rendah $(8 \%)$.

2. Persentase banyaknya mahasiswa yang memahami pengertian rob masuk dalam kategori tinggi $(73,38 \%)$.

3. Pengetahuan mahasiswa dalam hal penyebab rob tergolong bervariasi.

4. Pengetahuan mahasiswa mengenai dampak dan upaya meminimalisasi tergolong tepat.

\subsection{Saran}

Dengan melihat hasil pembahasan di atas, saran yang dapat diberikan adalah bahwa mahasiswa Pendidikan Matematika Universitas Pekalongan perlu memperluas wawasan mereka mengenai hal-hal yang terjadi di sekitar mereka. Banyak hal yang tampak sepele dan tidak berguna dapat dijadikan alat dalam pembelajaran kelak ketika menjadi guru. Selain itu, seharusnya mahasiswa selalu berlatih untuk berpikiran kritis dan memiliki empati terhadap sekeliling mereka.

\section{DAFTAR PUSTAKA}

Abd-Elhamid, H. and Javadi, A. (2008). An Investigation into Control of Saltwater Intrusion Considering the Effects of Climate Change and Sea Level Rise. In Proceedings of the 20th Salt Water Intrusion Meeting, Naples, Florida.

Arikunto, S. (2010). Suatu Pendekatan Praktik. Cetakan ke-14. Jakarta.

de Melo, M. T. C. (2015). COASTAL AQUIFERS understanding saltwater intrusion.

Gall, M. D., Gall, J. P., and Borg, W. R. (2003). Educational Research An Introduction. Pearson Education Inc., USA.

Nugroho, S. H. (2013). Prediksi luas genangan pasang surut (rob) berdasarkan analisis data spasial di Kota Semarang, Indonesia. Jurnal Lingkungan dan Bencana Geologi, Vol. 04 (No. 1):hal. 71-87.

Pilgrimm, L. (2015). Salt Water in Coastal Aquifiers. Fredericton, New Brunswick, Canada.

Plomp, T. (2007). Educational Design Research: an Introduction. In An Introduction to Educational Design Research, pages 9-36. Netherlands institute for curriculum development (SLO).

Sugiyono, D. R. (2006). Statistika untuk penelitian. Bandung: CV. Alfabeta.

Supriyadi and Khumaedi (2016). Edukasi Fenomena Amblesan-Intrusi Air Laut dan Penanggulangannya di Semarang Utara. Abdimas, Vol. 20(No. 1):hal. 55-60.

Thiagarajan, S., Semmel, D. S., and Semmel, M. I. (1974). Instructional Development for Training Teachers of Expectional Children. Leadership Training Institute/Special Education, University of Minnesota, Minneapolis, Minnesota. 